\title{
Conhecimento e significado para funcionárias de indústrias têxteis sobre prevenção do câncer do colo-uterino e detecção precoce do câncer da mama
}

\author{
Knowledge and Meaning in the Prevention of Uterine Cancer and Early Detection of \\ Breast Cancer in Female Textile Workers
}

\author{
Maria de Lourdes Marques Ferreira ${ }^{1}$ e Cristiane de Oliveira ${ }^{2}$
}

\begin{abstract}
Resumo
Verificar o conhecimento sobre o exame preventivo do câncer cérvico-uterino, detecção precoce do câncer da mama e compreender os sentimentos e significados atribuídos pelas mulheres ao serem submetidas a esses foram os objetivos deste estudo. A pesquisa foi realizada em duas indústrias têxteis, com aplicação de formulários contendo perguntas abertas efechadas, em uma população de 81 mulheres. 0 s dadosforam analisados descritivamente e as perguntas abertas através da análise de conteúdo. Verificou-se que, quanto ao Papanicolaou, a maioria o faz regularmente e conhece o objetivo pelo qual é feito, bem como ao auto-exame da mama (AEM) e exame clínico. A maior parte delas nunca realizou a mamografia. O s significados do preventivo e AEM foram de tranqüilidade, segurança, saúde e vida, detecção precoce e auto cuidado. O s sentimentos de sensação de desconforto, vergonha e constrangimento, ficando estes na dependência do profissional que o realiza, foram expressos com relação à realização do Papanicolaou. Para uma maior adesão, acredita-se na orientação contínua e consciente da importância da prevenção e detecção precoce através do diálogo, sensibilidade e empatia, como estratégia.
\end{abstract}

Palavras-chave: Câncer do colo-uterino; M ama; Prevenção; Diagnóstico precoce; Saúde da mulher.

\begin{abstract}
The aim of this study was to verify women's knowledge on preventive testing for cervical cancer and early detection of breast cancer and to understand the feelings and meanings ascribed by women submitting to these tests. The research was conducted in two textile factories, applying questionnaires with both open and closed questions in a sample of 81 women. The data were analyzed descriptively and the open questions were submitted to content analysis. The majority of the women had regular Pap smears and were familiar with its purpose, and also did breast self-examination (BSE) and clinical examinations. The majority had never had a mammogram. The meanings ascribed to the preventive examination and BSE were tranquility, security, health and life, early detection, and selfcare. D epending on the healthcare professional performing the examination, feelings of discomfort, shame, and embarrassment were associated with the Pap smear. To increase adherence, we favor a strategy of ongoing and conscientious orientation concerning the importance of prevention and early detection through dialogue, awarenessraising, and empathy.
\end{abstract}

Key words: Cervical cancer; Breast cancer; Prevention; Early detection; Women's health.

${ }_{1}^{1}$ Professora D outora Assistente na disciplina de Enfermagem Ginecológica $\mathrm{O}$ bstétrica e N eonatal do D epartamento de Enfermagem da Faculdade de M edicina de Botucatu - UNESP

2 Enfermeira do Departamento de Enfermagem da Faculdade de M edicina de Botucatu - UNESP

Endereço para correspondência: D epto. de Enfermagem - Faculdade de M edicina - UNESP - Campus - 18618-970 - Botucatu - SP

E-mail: malusa@fmb.unesp.br 


\section{INTRODUÇÃO}

0 câncer constitui um problema de saúde pública, cuja prevenção e controle deverão continuar a ser priorizados em todos os estados da União, mesmo naqueles onde, aparentemente, a população ainda apresenta um menor risco de adoecer dessa doença. ${ }^{1}$

As informações processadas pelos Registros de Câncer de Base Populacional, disponíveis em 16 cidades brasileiras, mostram que na década de 90, o câncer da mama foi o mais freqüente no país. As maiores taxas de incidência foram observadas em São Paulo, no Distrito Federal e em Porto Alegre. ${ }^{2}$

0 câncer da mama representa a primeira causa de morte, por câncer, entre as mulheres, com uma variação percentual relativa de mais de $80 \%$ em pouco mais de duas décadas em que a taxa de mortalidade padronizada por idade, por 100.000 mulheres, aumentou de 5,77 em 1979 para 9,74 em 2000.3

Já o câncer do colo do útero é o mais incidente na região $\mathrm{N}$ orte, ficando com a segunda posição na região $N$ ordeste e ocupando o terceiro lugar nas regiões $C$ entro0 este, Sudeste e Sul. ${ }^{1}$ É uma doença crônica que pode ocorrer a partir de mudanças intra-epiteliais e que pode, no período médio de cinco a seis anos, se transformar em processo invasor. Assim, a forma mais eficaz de controlar esse tipo de tumor é diagnosticar e tratar as lesões precursoras (neoplasias intra-epiteliais), e as lesões tumorais invasoras em seus estágios iniciais, quando a cura é possível em praticamente $100 \%$ dos casos. ${ }^{4}$

É bem conhecido que o câncer do colo uterino representa uma das causas de óbito mais freqüente na população feminina da América Latina, onde as taxas deincidência encontram-se entre as mais altas do mundo. Esta situação pode ser atribuída à falta ou à deficiência de ações preventivas, em que um programa eficaz de screening continua sendo um desafio. ${ }^{5}$

No Brasil, o M inistério da Saúde, para controlar o câncer cérvico-uterino, em 1988, adotou a normada 0 M S a qual propõe realizar 0 exame citológico nas mulheres entre 25 e 60 anos, a cada três anos após dois resultados negativos com intervalo anual, ainda que notadamente haja grande deficiência de recursos na área de saúde. ${ }^{5}$

As taxas de incidência de lesões pré-invasivas do câncer do colo uterino, moderadas e graves, têm aumentado nas mulheres mais jovens. Podese pressupor que tais resultados ocorram porque as mulheres estão iniciando a atividade sexual mais precocemente. ${ }^{5}$

0 câncer cérvico-uterino está relacionado com baixos níveis sócio-econômicos; com a conduta sexual, como precocidade do início da atividade sexual e promiscuidade; com o hábito de fumar e com fatores nutricionais, como a carência de vitamina $A .{ }^{6}$

A estratégia utilizada para detecção precoce da doença (prevenção secundária) ,no Brasil, é a realização da citologia cervical, conhecida popularmente como exame de Papanicolaou. ${ }^{7}$

Já no caso do câncer da mama, embora tenham sido identificados alguns fatores ambientais ou comportamentais associados a um risco aumentado, estudos epidemiológicos não fornecem evidências conclusivas que justifiquem a recomendação de estratégias específicas de prevenção. ${ }^{2} 0$ que se procura é a detecção precoce, porém na grande maioria dos casos ele é diagnosticado em estágios não iniciais, assim, falta-nos programas de rastreamento realmente efetivos, visando à detecção precoce das formas sub-clínicas lesões não pal páveis. Com isso, as chances de cura, bem como a instituição de terapia cirúrgica menos agressiva, ficam cada vez mais distantes. ${ }^{8}$

Almejando realizar a detecção precoce, o Instituto $\mathrm{N}$ acional de Câncer (INCA) tem se esforçado e desempenhado importante papel no desenvolvimento das ações nacionais orientadas para a prevenção e controle do câncer. Entre essas, se destacam as atividades relacionadas à vigilância do câncer, realizadas com base nas informações obtidas dos Registros de Câncer de Base Populacional (RCBP), os quais são supervisionados pelo IN CA/M S, e do Sistema de Informação sobre M ortalidade (SIM ), do M inistério da Saúde, centralizado nacionalmente pela Secretaria de Vigilância à Saúde SV S/M S. ${ }^{9}$

A mamografia (M G) convencional é o método de escolha para a detecção precoce nos programas de rastreamento do câncer da mama. A mortalidade pode ser reduzida em aproximadamente $30 \%$ por meio de programas de screening. ${ }^{8}$ Todavia, 0 exame de imagem ideal para o diagnóstico precoce, ainda, não foi perfeitamente desenvolvido.

A mamografia é um método de avaliação por imagem das lesões palpáveis em mulheres com idade igual ou superior a 35 anos. Podendo ser essa complementada pela ultrasonografia. ${ }^{2}$

O Exame Clínico das M amas deve ser realizado anualmente, para todas as mulheres com 40 anos ou mais. É parte fundamental da propedêutica para 0 diagnóstico de câncer da mama e deve ser realizado como parte do exame físico e ginecológico, constituindo a base para a solicitação dos exames complementares. ${ }^{2}$

0 auto-exame das mamas não deve substituir 0 exame clínico realizado por profissional de saúdetreinado para essa atividade. Entretanto, o exame das mamas pela própria mulher ajuda no conhecimento do corpo e deve estar contemplado nas ações de educação para a saúde. ${ }^{10}$ 
Visando este conhecimento e nos apropriando de que somos profissionais da saúde responsáveis pela educação da população para prevenção e detecção precoce de doenças, é que orientamos as mulheres das unidades de saúde em que atuamos para a realização do auto-exame das mamas. $E$ acreditamos que ao conhecerem melhor 0 seu corpo poderão detectar pequenas alterações morfológicas na mama seja ela benigna ou maligna.

Utilizando-se do auto-exame da mama como instrumento de detecção precoce do câncer da mama, e acreditando-se na educação da mulher para realizá-lo, se vê a oportunidade maior de reconhecer a doença neoplásica da mama em um estágio de desenvolvimento inicial e curável, o que é de igual interesse para os médicos que interpretam estes sintomas. ${ }^{11}$

$M$ as, o que usualmente se vê na prática é que as mulheres encontram as al terações acidentalmente, passando a mão sobre a mama, enquanto se banham ou se vestem e, em geral, ficam muito assustadas temendo 0 câncer da mama. ${ }^{11}$

Atuando em duas indústrias têxteis, cuja maioria de seus funcionários é constituída por mulheres, há al guns anos, percebemos que elas, muitas vezes, demonstram constrangimento, ansiedade, preocupações ao serem submetidas ao exame citológico e exame clínico das mamas. Assim, vimos como possibilidade, com a realização deste estudo, a verificação do conhecimento a respeito dessas neoplasias, bem como uma aproximação dos sentimentos e experiências dessas mulheres ao vivenciarem a detecção precoce e prevenção.

U ma vez conhecendo a vivência das mulheres, podemos planejar eadequar as orientações baseadas em necessidades apontadas a partir dos significados por elas atribuídos.

O s objetivos deste estudo foram verificar 0 conhecimento que as funcionárias das indústrias têxteis têm sobre o exame preventivo do câncer cérvico-uterino e auto-exame, exame clínico e mamografia para detecção precoce do câncer da mama e compreender os sentimentos e as experiências dessas mulheres ao submeterem-se ao exame de Papanicolaou eao realizarem auto-exame, exame clínico e mamografia para detecção precoce do câncer da mama.

\section{METODOLOGIA}

\section{ProcediMENTOS METODOLÓGICOS}

Foram utilizados dois formulários com perguntas fechadas e abertas.

A coleta de dados foi realizada no período de julho a setembro de 2003 no próprio ambiente de trabalho, onde se entrevistaram 81 mulheres, que aceitaram participar do estudo. $\mathrm{N}$ ão houve convite recusado, todas as mulheres convidadas participaram.

A nomenclatura utilizada para a identificação das descrições obtidas pelas mulheres foi a letra $M$, seguida do número de ordem da entrevista. Assim, no relato das descrições aparece $M 1, M 2 \ldots$

Foi garantido 0 anonimato e solicitada a permissão para gravar as falas relacionadas às questões abertas dos formulários para as mulheres que aceitaram participar da pesquisa e que assinaram o consentimento livre e esclarecido do paciente. 0 projeto foi aprovado pelo Comitê de Ética em Pesquisa da Faculdade de M edicina de Botucatu - UNESP.

\section{ANÁLISE DOS DADOS}

A análise dos dados foi realizada em dois momentos, por conter nos questionários perguntas fechadas e abertas. Inicialmente, os resultados foram analisados descritivamente, expressos em valores numéricos absolutos e relativos e, em segundo momento, as perguntas abertas foram analisadas segundo a técnica de análise de conteúdo ${ }^{12}$, a qual desdobra-se em três etapas: pré-análise, em que pudemos realizar a leitura dos depoimentos; exploração do material, que nos permitiu classificar as descrições em sistema de categorias reunidas de acordo com o significado; e tratamento dos resultados obtidos einterpretação, através de recorte, agregação e enumeração e, uma vez determinadas as unidades de significação, passa-se à interpretação dessas.

A opção pela análise temática pareceu-nos pertinente visto que a mesma se presta a estudar tendências, valores, crenças e conteúdos em destaque sobre temas específicos. Assim, o presente estudo analisou, enquanto temática, o significado atribuído pelas mulheres na prevenção do câncer do colo-uterino e detecção precoce do câncer da mama.

\section{RESULTADOS E DISCUSSÃO}

\section{CARACTERIZAÇÃO DAS MULHERES}

A idade das mulheres que trabalham nas indústrias têxteis variou de 20 a 52 anos, sendo a faixa etária de 30 a 40 anos a mais encontrada (43,2\%). Q uanto à situação conjugal, identificou-seque $63,0 \%$ das mulheres relataram ser casadas.

No que diz respeito à categoria profissional, verificamos que a maioria das funcionárias, $67,9 \%$, era costureira.

Quanto ao grau de escolaridade, 45 (55,6\%) funcionárias cursaram o 1 음au completo ou incompleto; $31(38,3 \%)$ freqüentaram a escola até o 20 grau completo ou incompleto; quatro $(4,9 \%)$ tinham o 30 grau completo 
ou incompleto e uma $(1,2 \%)$ relatou ser analfabeta.

\section{REALIZAÇÃO DO EXAME DE PAPANICOLAOU}

Das 81 mulheres que participaram, a maioria, ou seja, $79(97,5 \%)$ referiu já ter realizado o exame preventivo do câncer cérvico-uterino. Esta grande proporção de mulheres que se submetem ao exame pode ser associada à maior divulgação da importância do exame de Papanicolaou ocorrida nos últimos anos, às campanhas promovidas pelo M inistério da Saúde e, também, ao fato dessas funcionárias terem a possibilidade de realização desse exame preventivo na própria unidade de trabalho.

A razão referida pelas duas mulheres que não se submeteram ao exame foi: "Porque nunca tive relação sexual" (M 77) e "Falta de tempo" (M 40). H á que se considerar, uma ampla gama de fatores que podem motivar a não realização do exame. Um deles pode estar relacionado ao dia-a-dia, repleto de afazeres que socialmente se vêem como necessários, considerando as funções de: mães, donas-decasa e "trabalhadoras". ${ }^{13}$

É de extrema importância estarmos informados sobre os motivos que fazem com que as mulheres não realizem o exame preventivo, para assim, podermos intervir aumentando a cobertura do mesmo e a adesão.

$\mathrm{N} 0$ que se refere à periodicidade de realização do Papanicolaou, 66 funcionárias $(83,5 \%)$ relataram que 0 fazem anualmente. Este resultado pode estar associado à possibilidade de realização fornecida pelo próprio trabalho, como já mencionado anteriormente. Cinco funcionárias $(6,3 \%)$ relataram que o fazem a cada seis meses; outras cinco funcionárias $(6,3 \%)$ disseram que o fazem a cada dois anos; uma (1,3\%) relatou que o faz a cada oito meses; outra $(1,3 \%)$ que o faz a cada três anos e outra (1,3\%) que o fez apenas uma vez.

Pode-se observar, portanto, com estes dados, que se tem uma boa adesão das funcionárias cuja periodicidade continua a ser anual, mesmo após recomendação do M inistério da Saúde para que seja feito a cada três anos, após dois exames negativos com intervalo anual entre eles. O ptou-se pela manutenção da realização anual do exame a pedido das mulheres que alegaram maior segurança e tranqüilidade na prevenção do câncer do colo-uterino. Como é realizada consulta de enfermagem, através do programa de extensão universitária há 10 anos, atendemos à solicitação das mulheres.

Das 79 mulheres que realizam o Papanicolaou, a maioria $(72,2 \%)$ referiu que aúltima vez que se submeteu ao exame foi há um ano, porcentagem esta, também vinculada ao fato das indústrias considerarem a importância do exame anual e viabilizar a realização do mesmo, através do programa de extensão universitária.
D ezoito mulheres $(22,8 \%)$ referiram que 0 tinham realizado no mesmo ano da pesquisa; duas $(2,5 \%)$ referiram que a última vez que o fizeram foi há dois anos e outras duas $(2,5 \%)$ disseram que foi há três anos.

Q uanto ao conhecimento do exame preventivo do câncer cérvico-uterino, apenas uma $(1,2 \%)$ relatou não conhecer a finalidade do mesmo. Tal fato mostra a necessidade de esclarecimento sistemático sobre a finalidade e periodicidade do exame, pois 0 desconhecimento pode contribuir para diminuir a aderência a este. $D$ entre os muitos fatores limitantes à realização do citopatológico, estão a falta de conhecimento quanto aos fatores causadores do câncer do colo-uterino e desconhecimento quanto à existência do exame e/ou sua utilidade, bem como a mistificação do câncer como doença fatal não resolvendo a prevenção. ${ }^{14}$ Entre aquelas que disseram conhecer a finalidade do Papanicolaou, $35(43,7 \%)$ o associaram à prevenção e detecção do câncer do colo do útero; 16 $(20,0 \%)$ indicaram que esse exame é realizado para prevenção de câncer e outros problemas uterinos e 22 $(27,5 \%)$ reportaram-se à detecção de doenças, infecções e feridas sem citarem o câncer propriamente.

A pesar da maioria relatar ter conhecimento, há grande inconsistência entre conhecimento e prática, pois muitas pessoas que parecem ter adquirido conhecimentos e atitudes favoráveis sobre prevenção não as incorporam no cotidiano do cuidado à própria saúde. ${ }^{13}$

O s locais de informação sobre o exame de Papanicolaou referidos pelas funcionárias foram bastante diversificados. Responderam que receberam informações com maior freqüência na Unidade Básica de Saúde, seguidamente com o ginecologista, no local de trabalho e, então, com amigos.

\section{SIGNIFICADO DO EXAME PREVENTIVO DE CÂNCER DO COLO- UTERINO PARA AS FUNCIONÁRIAS DAS INDÚSTRIAS TÊXTEIS}

\section{Tranqüilidade, alívio e segurança}

O câncer é uma doença crônico-degenerativa que provoca muito pavor nas pessoas. Assim, muitas mulheres relatam sentirem-se tranqüilas após a realização do exame preventivo, por saber que não possuem essa doença tão temida por todos. $0 \mathrm{~s}$ relatos que se seguem esclarecem esse significado:

"Passa tranqüilidade, pois fico sabendo o que está acontecendo comigo" (M 13).

"... a gente sente-se aliviada depois, fica menos preocupada, pois é um problema que está dando tanto, tanta mulher morre desse problema..." (M 62).

A partir do relato acima, se pode observar a grande 
correlação que é feita entre 0 câncer e a morte, daí 0 alívio por saber em que não apresentam esta patologia.

No conjunto das modificações que o homem sofre no decorrer de sua existência, há duas mudanças que se destacam e predominam sobre as outras: o nascimento e a morte. Rechaçada como tabu na vida cotidiana, a morte está, não obstante, presente, em todos os momentos, nas mitologias, no ritual, no inconsciente. Porém, a morte é banida das conversas, obscurecida por metáforas e escondida das crianças. ${ }^{13}$

Saúde uterina e vida

O "motivo para" representa um contexto de significado que é construído sobre o contexto das experiências disponíveis no momento da projeção da ação, sendo essa categoria essencialmente subjetiva, somente a pessoa pode definir o seu projeto de ação, seu desempenho social. ${ }^{15}$

Pensando-se sempre na vida ativa, pode-se notar a evidente preocupação dessas funcionárias quanto ao trabal ho, maternidade e, sobretudo à vida quando são questionadas sobre o significado do exame de Papanicolaou:

"P reservar o meu futuro, pois se um dia eu quiser ser mãe e se eu tiver algum problema, já vou descobrir antes.. e maiores são as minhas chances.." (M 40).

"Significa a vida da gente, que é muito mais importante..." (M 46).

"Para a minha saúde, isto tem um significado muito grande,... pois sem a saúde a gente não consegue trabalhar, se sente inútil" (M 66).

Com esta declaração acima citada, fica evidente a ligação entre a doença e a sensação de inutilidade, pois com a conquista cada vez maior da mulher no mercado de trabalho, essa tem a necessidade de manter-se sempre ativa e sentir-se útil.

\section{Detecção precoce}

Dado o pavor provocado pelo câncer, as mulheres temem apresentar algo sério e relatam a importância de que se houver algo, no começo o tratamento pode ter mais sucesso, evidenciando assim em seus relatos 0 reconhecimento da importância da realização do exame:

"... logo no começo fica mais fácil de ser tratado e, quanto mais tempo a gente deixar, pior fica" (M 44).

"Porque se você tiver um câncer e ver no início, aí tem cura, tem como tratar, cuidar" (M 54).

A assimilação da prática do Papanicolaou passa pela assimilação dos benefícios, de sua eficácia e importância.

Aumentar a oferta de exames com a realização do
Papanicolaou em mulheres que nunca ou raramente freqüentam os serviços de saúde é conduta eficaz para a redução da morbi-mortalidade da doença. E acredita-se que este se configure como um dos maiores desafios dos órgãos gestores da saúde. ${ }^{16}$

Essas falas evidenciam, muito bem, a consciência que essas mulheres têm quanto à detecção precoce e chances de cura.

\section{Autocuidado}

0 que se opõe ao descuido e ao descaso é o cuidado. Cuidar é mais que um ato; é uma atitude. 0 cuidado se encontra na raiz primeira do ser humano, antes que ele faça qualquer coisa. Sem o cuidado, o homem deixa de ser humano. ${ }^{17}$

"Cuidado com a minha saúde, porquese vocêtem al gum problema e não sabe, às vezes, fica tarde.." (M 42).

"U ma coisa boa, pois pelo menos eu sei o que está acontecendo, é um cuidado comigo mesma, com a minha saúde" (M 80).

\section{SENTIMENTO DAS MULHERES NA REALIZAÇÃO DO PAPANICOLAOU}

\section{Sensação de desconforto}

É bastante compreensível este sentimento por parte das mulheres, visto o preconceito que ronda os exames ginecológicos.

"N ão gosto de fazer este exame, acho chato" (M 1).

"Acho incômodo, demorado" (M 14).

"Acho que é um exame um pouco dolorido" (M 31).

O s profissionais de saúde devem expor somente a parte do corpo necessária para a realização do exame, evitar o trânsito desrespeitoso de profissionais na sala de exame e encorajar a mulher tentando evitar o medo e a vergonha. ${ }^{18}$

\section{Compreensão de normalidade}

O postamente aos depoimentos anteriores, muitas mulheres relataram já estarem habituadas com esse exame e, assim, o consideram como um exame igual a qualquer outro, desmistificando qualquer preconceito.

"Acho normal, não me importo" (M 2).

"N ão sinto nada, nada, nada... acho normal como se fosse outro exame" (M 64).

A partir da associação feita entre a normalidade e 0 hábito de realização do Papanicolaou, essas mulheres relatam não se sentirem incomodadas em realizá-lo, fazendo esse parte de seu cotidiano. 
Sentimentos controversos

Os depoimentos, a seguir, mostram que apesar de algumas mulheres relatarem aspectos negativos em relação ao exame, reconhecem a necessidade e importância de sua realização.

"N ão gosto de me submeter ao exame, mas acho que temos que ter consciência" (M 6).

"Acho incômodo, pois, às vezes, fica dolorido, porém, acho importante e que vale a pena fazer" (M 8).

Em estudos realizados sobre a apreensão dos significados atribuídos pelas mulheres ao exame ginecológico, de caráter preventivo, as mulheres também mostraram por meio de seus sentimentos que na relação entre o "necessitar" e o "não querer" a responsabilidade pelo próprio corpo suplanta os sentimentos desfavoráveis. ${ }^{19,20}$

\section{Sentimentos de vergonha e constrangimento}

As verbalizações, a seguir, mostram que muitas mulheres referem-se a este exame preventivo como um exame constrangedor.

"Fico muito constrangida ao realizá-lo etenho medo" (M 26).

"Sinto muita vergonha, este é o meu maior obstáculo, por isso fico tempo sem fazer" (M 49).

Estudos sobre as atitudes das mulheres brasileiras quanto à prevenção e o não atendimento aos programas de captação mostram que as principais causas de resistência estariam ligadas às questões culturais, tais como, medo de doer, vergonha, religião, desconhecimento do exame ende realizá-lo e o parceiro quenão permitequea mulher realizeo exame preventivo. 0 medo pode estar também relacionado com a possibilidade do resultado ser positivo para câncer. $\mathrm{N}$ esses casos, a mulher realiza o exame e não retorna para saber do resultado. ${ }^{21}$

A submissão aos maridos pode dificultar a formação de uma atitude adequada em relação ao Papanicolaou. $N$ esse sentido, as atividades educativas da equipe de saúde devem ser ampliadas aos casais com o objetivo de conscientizar os parceiros para a estimulação e facilitação das mulheres a atitudes femininas favoráveis ao exame.22

$\mathrm{N}$ a unidade de saúde que atendemos, há vários anos, se realiza uma reunião de orientação com grupos de mulheres na oportunidade da entrega do resultado, para estimular a busca do resultado, bem como orientá-las nas suas dúvidas em relação ao câncer do colo uterino e ao exame.

O s profissionais de saúde devem procurar maneiras para tentar minimizar esse sentimento de vergonha, 0 qual pode até mesmo levar a mulher a deixar de realizar a prevenção, como citado acima. Por isso, deve-se procurar demonstrar empatia e fazer com que a mulher sinta-se o mais à vontade possível.

"Eu sou muito vergonhosa, tenho muita vergonha..." (M 51).

D eve-se levar em consideração, também, 0 fato de muitas pessoas serem extremamente tímidas, independente da circunstância em que se encontram e, é claro que nesta situação a timidez tende a aumentar muito. Então, o atendimento dessas pessoas requer maior sensibilidade e compreensão.

"Tenho vergonha, muita vergonha, fico muito inibida, às vezes, até chegando a achar que está dolorido, mas não é; a vergonha que me faz achar que etá doendo" (M 65).

Esse sentimento de vergonha exacerbado dificulta a realização do exame, pois a mulher não consegue relaxar, e isto pode fazer com que esse exame torne-se mais dolorido, pela contração da musculatura pélvica.

"Sinto muita vergonha, acho muito ruim, poisjá tenho vergonha pela posição e, além de tudo, ficam fazendo pergunta" (M 68).

Portanto, muitas vezes, por vergonha, preconceito e medo de realizarem os exames ginecológicos de rotina, as mulheres colocam desnecessariamente sua saúde em risco.

\section{Sentimentos que dependem do profissional que 0} realiza

Podemos compreender na fala das mulheres, que muitos de seus sentimentos estão vinculados ao profissional que realiza o exame, partilhando com ele sua ansiedade e sua expectativa.

Para garantir a adesão das clientes ao programa preventivo, é necessário que o profissional supere as expectativas das mesmas, desenvolvendo um clima de empatia e confiança. U ma prática mais humanizada, desenvolvendo a capacidade de interação, agindo não só com preparo técnico, mas também com intuição e sensibilidade, certamente contribuirá para a qualidade do atendimento prestado à mulher durante a realização do exame. ${ }^{13}$

"... envergonhada todo mundo fica, principalmente se for homem, porque eu não gosto de fazer com homem" (M 46).

"... tenho vergonha com homem, mas com mulher não" (M 57).

Fica bastante evidente a identificação com a profissional feminina, que pode estar associada à partilha das mesmas necessidades de gênero. Isto foi citado por mulheres como um fator positivo para a realização do exame preventivo do câncer do colouterino.

0 atendimento de quase todas as necessidades 
humanas básicas do paciente depende, em várias circunstâncias, do processo de comunicação que ocorre entre ele e 0 profissional. ${ }^{23}$

\section{REALIZAÇÃO DO AUTO-EXAME DAS MAMAS}

A maioria, ou seja, 60 mulheres $(74,0 \%)$ referiram que fazem 0 auto-exame das mamas; enquanto 21 mulheres $(26,0 \%)$ relataram quenão realizam esse exame.

0 s motivos al egados pelas mulheres que não realizam 0 auto-exame das mamas foram dificuldade para reconhecer as estruturas normais e as possíveis alterações (três mulheres); esquecimento (17 mulheres) e por não acreditar que ten ha valor 0 auto-exame das mamas (uma mulher).

No que diz respeito à periodicidade da realização do auto-exame das mamas, 40 mulheres $(66,7 \%)$ relataram que o fazem uma vez por mês; sete mulheres $(11,7 \%)$ relataram que o fazem uma vez por semana; cinco (8,3\%) disseram que o fazem uma vez a cada dois meses; três $(5,0 \%)$ referiram que o fazem duas vezes por semana; uma $(1,66 \%)$ relatou o fazer quase diariamente; outra $(1,66 \%)$ três vezes por semana; uma $(1,66 \%)$ relatou 0 fazer três vezes mês mês; outra $(1,66 \%)$ duas vezes por mês e outra $(1,66 \%)$ uma vez a cada três meses.

Pode-se notar com estes dados que apesar de al gumas mulheres, ainda, não saberem muito bem com que intervalo devem realizar o auto-exame das mamas, a maioria, conhece a periodicidade recomendada. Vale ressaltar que essas mulheres que demonstraram desconhecer o período de realização foram orientadas quanto ao mesmo.

Cabe ao profissional de saúde exercer não somente atividade assistencial, mas um papel educativo, fornecendo à população informações que lhe sejam úteis na prevenção, controle e combate das enfermidades. D eve, também, incentivar a mulher para incorporar as orientações a respeito de sua saúde ao seu comportamento, propiciando dessa forma 0 auto cuidado e conhecimento de seu corpo. ${ }^{24}$

SIGNIFICADO DO AUTO-EXAME DAS MAMAS PARA AS MULHERES QUE O REALIZAM

\section{Prevenção}

Visto o medo que essas mulheres têm de ter um câncer da mama, muitas vêem como finalidade do autoexame das mamas a possibilidade de evitar 0 aparecimento do câncer e de outros problemas.

"A gente está prevenindo o câncer de mama, porque como eu já tive em casa, a gente fica mais esperta" (M 70).

"P revenir contra o câncer é muito bom, principalmente das mamas, porque quando a gente chega a perder 0 sei o, a gente se sente arrasada" (M 43).

Com o relato anterior, percebe-se a idéia de mutilação que muitas mulheres têm, ao pensarem no câncer da mama. Isto é extremamente traumatizante para as mulheres, visto o valor que é dado por nossa sociedade ao corpo.

O corpo humano é socialmente concebido. Cada sociedade elege certo número de atributos que configura o que o homem deve ser, tanto do ponto de vista intelectual ou moral quanto do ponto de vista físico. 0 corpo é pouco mais que uma massa de modelagem à qual a sociedade imprime formas segundo suas próprias disposições, formas em que a sociedade projeta a fisionomia do seu próprio espírito. ${ }^{25}$

\section{Detecção precoce}

D ado que, através do diagnóstico precoce, 0 tratamento e a cura podem ser alcançados, daí a preocupação de muitas mulheres neste aspecto.

"O bservar se tem algum problema nas mamas, porque se houver... você já corre e pode tratar a tempo" (M 39).

"Para ver se tem algum carocinho, para pegar enquanto é tempo, porque aí se for algum problema, você descobre em tempo e tem cura" (M 54).

0 acometimento como o câncer da mama é visto como potencialmente estressor e provoca uma série de transformações na vida, tanto da mulher acometida quanto de seus familiares, pois além do medo da morte quea doença suscita, há, também, a ameaça da mutilação damama, queéum símbolo importante de feminilidade, sexualidade, erotismo, maternidade e outros. ${ }^{26}$

\section{Autocuidado}

Cuidar-se é extremamente importante, pois quem é são pode ficar doente. A doença significa um dano à totalidade da existência. Portanto, não é uma parte que está doente, mas é a vida que adoece em suas várias dimensões: em relação a si mesmo. ${ }^{17}$

"Significa cuidado comigo mesma" (M 13).

"É um cuidado com o meu corpo" (M 40).

\section{REALIZAÇÃO DO EXAME CLINIICO DAS MAMAS}

Apenas uma mulher $(1,2 \%)$ relatou que não o tinha realizado. A justificativa apresentada por ela foi "N unca fui ao ginecologista" (M 40).

Ao perguntarmos sobre a freqüência da realização do exame clínico das mamas, percebemos que 67 mulheres $(83,8 \%)$ o fazem uma vez por ano; seis mulheres $(7,5 \%) 0$ fazem uma vez a cada dois anos; cinco mulheres $(6,3 \%) 0$ 
fazem uma vez a cada seis meses; uma mulher $(1,2 \%)$ o faz a cada três anos e outra $(1,2 \%)$ o faz a cada oito meses.

A partir destes dados, podemos concluir que apesar de algumas mulheres deixarem a desejar quanto à realização desse exame, a maioria o faz periodicamente.

Q uanto ao profissional que realizou o exame, 49 mulheres $(61,3 \%)$ referiram que este foi feito por um médico e 31 mulheres $(38,7 \%)$ relataram que este foi realizado por uma enfermeira.

\section{REALIZAÇÃO DA MAMOGRAFIA}

Q uanto à mamografia, 63 mulheres (77,8\% ) disseram que nunca a realizaram, enquanto que 18 mulheres $(22,2 \%)$ relataram já terem feito esse exame.

Este reduzido número pode ser explicado pelo fato da maior parte das entrevistadas estar na faixa etária de 30 a 40 anos, já que a partir dessa é que normalmente começam a ser feitas as mamografias, a não ser que haja algum problema anteriormente.

O s motivos alegados pelas mulheres que nunca realizaram a mamografia foram: "N unca fui encaminhada"; "N ão houve nenhum problema" e, apenas uma mulher relatou: "N unca fui, apesar de ter sido encaminhada" (M 54). Vale ressaltar quetodas as mulheres com mais de 40 anos foram orientadas quanto à importância e necessidade da realização desse exame.

A falta de solicitação médica para a realização da mamografia para rastreamento do câncer da mama, em mulheres acima de 40 anos de idade, bem como 0 desconhecimento da importância desse exame, representam uma justificativa para a sua não realização. ${ }^{27}$

Já os motivos al egados pelas mulheres que realizaram a mamografia foram ou por idade para o controle preventivo (seis mulheres) ou por problemas específicos, como aparecimentos denódulos, dorese secreções (12 mulheres).

Portanto, deve-se investir cada vez mais em campanhas de orientação e conscientização da população para a realização desse exame, pois pudemos perceber que ainda há mulheres que desconhecem esse exame e, é importante ressaltar que estas foram esclarecidas quanto ao mesmo.

\section{SIGNIFICADO DA MAMOGRAFIA PARA AS MULHERES QUE A REALIZAM}

\section{Importante para tranqüilizar-se}

Visto o pavor que as mulheres têm de aceitar o câncer, que é uma doença extremamente temida por todos, a mamografia, de acordo com relatos abaixo, muitas vezes, serve para tranqüilizar estas mulheres.

"Ótimo, pois me tranqüilizou..." (M 9).
"Pra mim, eu acho que tem uma importância muito grande, pois eu tinha muita dúvida, eu ficava muito nervosa, porque eu achava que tinha alguma coisa e, assim, tirei minhas dúvidas.." (M 51).

A mamografia é indicada em duas situações distintas; para mulheres com achados clínicos que levam à suspeita de câncer da mama e para as assintomáticas como rastreamento do câncer da mama; e é nessa segunda situação que as mulheres ficam mais tranqüilas, podendo fazer um diagnóstico mesmo antes dos sintomas aparecerem. ${ }^{27}$

\section{Sentimentos ambíguos}

Algumas mulheres reagem negativamente a esse exame, embora ressaltem a sua importância.

"Achei traumatizante, extremamente dolorido, porém, absolutamente necessário" (M 24).

"M uito bom, pois fiquei sossegada..., porém, ache um pouco dolorido, pois parece um sanduíche- aperta" (M 79).

Um achado interessante, em estudos semelhantes, mostrou que a expressão "medo do exame" foi razão praticamente desprezível para as mulheres que nunca tinham se submetido à mamografia. ${ }^{27}$

\section{Autocuidado}

Como já mencionado em outras categorizações, cuidar-se é estimar-se e proteger-se e, então, devemos saber nos cuidar.

"Si gnifica prevenção e cuidado comigo mesma" (M 24).

O cuidado significa uma relação amorosa com a realidade. I mporta em um investimento de zelo, desvelo, solicitude, atenção e proteção para com aquilo que tem valor e interesse para nós. ${ }^{17} \mathrm{~A}$ preocupação com a saúde é revelada no autocuidado.

\section{CONSIDERAÇÕES FINAIS}

A análise dos dados apresentados colocou em evidência as principais causas e dificuldades que as mulheres apresentaram na realização do exame citológico e detecção precoce do câncer da mama.

Pudemos verificar que ainda há mulheres, embora em uma porcentagem pequena, que não se submetem aos exames ginecológicos de rotina, desconhecem a razão pela qual são feitos e que não foram orientadas quanto à periodicidade dos mesmos.

Muitos fatores podem ser destacados como determinantes deste resultado, como a falta de conhecimento e o dia-a-dia bastante corrido que essas mulheres apresentam, levando-as a esquecer, até mesmo, 
do cuidado consigo próprias.

Por um lado, dessa forma, continua sendo um desafio para todos nós, profissionais de saúde, garantir a adesão dessas mulheres ao programa preventivo do câncer do colouterino e ao de detecção precoce do câncer da mama.

Por outro lado, verificamos que a grande maioria das mulheres possui conhecimento sobre os exames. Q uanto aos sentimentos, os de vergonha para a real ização do Papanicolaou e esquecimento do auto-exame das mamas são relevantes entre eles.

Para uma maior adesão, acredita-se na orientação contínua e consciente da importância da prevenção e detecção precoce através do diálogo, sensibilidade e empatia, como estratégia.

O uvir as mulheres que fizeram parte desse estudo permitiu-nos vislumbrar caminhos que possam favorecer a aderência aos exames.

Caminhos como uma prática mais humanizada com desenvolvimento de uma relação empática, considerando as angústias, medo, vergonha e aflição das mulheres atendidas. Há que se considerar na assistência humanizada a cliente como pessoa que traz consigo uma bagagem social, cultural e religiosa.

Esse caminho nos mostra que é preciso transcender a assistência biológica.

Portanto, esse estudo possibilitou-nos um novo olhar a essas mulheres, conhecendo suas próprias vivências em relação a esses exames, para que, assim, possamos enfrentar esta problemática e chegar a uma cobertura mais próxima do ideal para a prevenção e detecção precoce do câncer da mama e colo uterino.

\section{REFERÊNCIAS BIBLOGRÁFICAS}

1. K ligerman J. Estimativas sobrea incidência emortalidade por câncer no Brasil: 2001. Rev Bras Cancerol. 2001;47(2):111- 4.

2. Instituto $N$ acional deC âncer; M inistério daSaúde Coordenação de Prevenção e Vigilância. Controle do câncer de mama: documento deconsenso. Rio deJaneiro: IN CA; 2004.

3. Instituto $\mathrm{N}$ acional deC âncer [homepagena Internet]. Rio de Janeiro: IN CA; c1996-2005 [citado em 9 set 2005]. Atlas de mortalidade por Câncer no Brasil: 1979-1999. Disponível em: http://www.inca.gov.br/atlas.

4. Instituto $\mathrm{N}$ acional de Câncer; M inistério da Saúde. N eoplasia intra-epitelial cervical: NIC. Rev BrasC ancerol. 2000;46(4): 355-7.

5. Zeferino LC, CostaAM , PanettaK, JorgeJPN . Screening da neoplasiacervical. J BrasG inecol. 1996; 106(11-12): 415-9.

6. Lopes ER, Rebelo M S, Abreu E, Silva VLC, Eisenberg ALA, Lavor M F. Comportamento da população brasileira feminina em relação ao câncer cérvico-uterino. J Bras
Ginecol. 1995;105:505-16.

7. Instituto $\mathrm{N}$ acional deC âncer [homepagenal nternet]. Rio de Janeiro: IN CA; c1996-2005 [citado em 9 set 2005]. Prevenção do câncer decolo uterino. D isponível em: http:/ /www.inca.gov.br/conteúdo.

8. Ricci M D, Pinotti M, Pinotti JA. Perspectivas da ultrasonografia na detecção ediagnóstico do câncer de mama. Rev Ginecol \& 0 bstet. 2000;11:156-60.

9. Instituto $\mathrm{N}$ acional de $\mathrm{C}$ âncer [homepagenal nternet]. Rio de Janeiro: IN CA; c1996-2005 [citado em 5 set 2005]. Câncer no Brasil: dados dos registros debase populacional. D isponível em: http://www.inca.gov.br/regpop/2003.

10. Instituto $\mathrm{N}$ acional deC âncer [homepagenal nternet]. Rio de Janeiro: IN CA; c1996-2005 [citado em 6 set 2005]. Programa $\mathrm{N}$ acional de $\mathrm{C}$ ontrole do $\mathrm{C}$ âncer de $\mathrm{C}$ olo e de M ama Viva Mulher. Disponível em: http:// www.inca.gov.br/conteudo.

11. $H$ aagensen $C D$. Papel da mulher no reconhecimento dos sintomas de doenças demama. In: D oenças damama. São Paulo: Roca; 1998. p.515-29.

12. Bardin L. Análise deC onteúdo. Lisboa: Personal; 1977.

13. M erighi M AB, Harmano L, Cavalcante LG. 0 exame preventivo do câncer cérvico-uterino:conhecimento e significado parafuncionárias deuma escola deenfermagem de uma instituição pública. Rev Esc Enferm USP. 2002;36(3):289-96.

14. Lazcano-Ponce EC, Castro R, Allen B. Barriers to early detection of cervical uterino câncer in M éxico. J Womens H ealth. 1999; 8(3):399-408.

15. Capalbo RYS. M etodologiadasciênciassociais afenomenologia deAlfred Schutz. 2aed. Londrina: UEL; 1998.

16. Instituto N acional de Câncer; M inistério da Saúde; Secretaria de Estado da Saúde. Coleta do papanicolaou e ensino do auto-exame da mama: manual de procedimentos técnicose administrativos. 2a ed. São Paulo: IN CA; 2004.

17. Boff L. Saber cuidar: ética do humano - compaixão pela terra. Rio de Janeiro: Vozes; 1999.

18. M oreira RM . Exame G inecológico: testes corados. Anais do 44을 Congresso Brasileiro de Ginecologia eO bstetrícia; 1991 N ov. 16-20; Brasília. Brasília: Sociedade de Ginecologiae O bstetrícia; 1995. p.20.

19. Lopes RLM . A mulher vivenciando o exameginecológico na prevenção do câncer cervicouterino. Rev Enferm UERJ . 1998; 2(2):165-70.

20. PaulaAF. D o outro lado do especulo: o examesob aótica da mulher queo vivencia[dissertação]. Belo H orizonte (M G): Escola deEnfermagem daU niversidade Federal deM inas Gerais; 2001.

21. Instituto $\mathrm{N}$ acional deC âncer [homepagenal nternet]. Rio de Janeiro: IN CA; c1996-2005 [citado em 6 set 2005]. Ações de enfermagem: ações de prevenção primária e secundária no controle do câncer. D isponível em: http:// www.inca.gov.br/conteudo. 
22. GamarraCJ; Paz EPA; Griep RH . Conhecimento, atitudes e prática do exame de papanicolaou entre mulheres argentinas. Rev Saúde Pública. 2005; 39(2):270-6.

23. Stefanelli M C. Comunicação com paciente: teoriaeensino. São Paulo: Robi;1996.

24. M onteiro APS, Arraes EPP, Pontes LB, Campos MSS, Ribeiro RF, Gonçalves REB. Auto exame das mamas: freqüência do conhecimento, prática efatores associados. Rev Bras G inecol 0 bstet. 2003;25(3):201-5.
25. Rodrigues]C. Tabu do corpo [dissertação]. Rio de]aneiro: U niversidadeF ederal do Rio deJ aneiro; 1983.

26. D uarte TP, Andrade N A. Enfrentando a mastectomia: análise dos relatos de mulheres mastectomizadas sobre questões ligadas à sexualidade. Estud Psicol. 2003;8(1):155-63.

27. G odinho ER, Koch $\mathrm{H}$. O perfil da mulher quesesubmete a mamografia em G oiânia: uma contribuição a bases para um programa de detecção precoce do câncer de mama. Radiol Bras. 2002;35(3):139-45. 


\section{ANEXO 1}

FORMULÁRIOI

Idade: ___ Situação conjugal:______ O cupação: ____ Escolaridade:___ RG da Unesp:

1) Você já fez o exame de Papanicolaou? ( )sim ( )não

2) Se sim, com que intervalo de tempo?

3) Se não, porque nunca fez?

4) Quais as razões que levam você a não fazer o exame de Papanicolaou ou demorar em fazer 0 controle?

5) Q ual foi a última vez que você fez este exame?

6) Sabe o motivo pelo qual é feito o exame de Papanicolaou?

( )sim ( )não Caso saiba, qual?

7) O nde você recebeu informação sobre o exame de Papanicolaou?

8) 0 que significa para você fazer o exame ginecológico para a prevenção de câncer de colo de útero? 0 que você sente quando se submete ao exame de Papanicolaou?

\section{ANEXO 2}

FORMULÁRIO II

1) Você realiza o Auto-Exame das M amas? （） sim （） não

2) Se sim, com que intervalo?

3) 0 que significa para você realizar o Auto- Exame das M amas?

4) Se não, porque não o faz?

5) Já realizou o Exame Clínico das M amas? ( ) sim （） não

6) Se sim, com que freqüência?

7) 0 exame clínico das mamas foi realizado por quem?

8) Se não, porque não realizou?

9) Já realizou a mamografia? ( ) sim （） não

10) Se sim, por que realizou?

11) 0 que significou para você ter realizado o exame?

12) Se não, por quê? (Se tiver mais de 40 anos - Encaminhar) 